\title{
Identifikasi Kesegaran Ikan Nila menggunakan Teknik Citra Digital
}

\author{
Juli Elprida Hutagalung ${ }^{1}$, Mhd Ihsan Pohan ${ }^{2}$, Yuli Happy Marpaung ${ }^{3}$ \\ 1, 2, 3 Universitas Negeri Medan, Jl. Willem Iskandar Pasar V Medan, Sumatera Utara, Indonesia \\ e-mail: julielpridahutagalung@gmail.com ${ }^{1}$,ihsanpohan@gmail.com ${ }^{2}$,yulihappymarpaung@gmail.com ${ }^{3}$
}

\begin{abstract}
Abstrak-Ikan banyak mengandung nutrisi yang sangat bermanfaat bagi tubuh, namun seringkali ikan diperdagangkan dalam keadaan sudah mati juga dalam keadaan masih hidup. Untuk mengamati kesegaran ikan nila dilakukan dengan pengenalan perubahan warna yang tampak pada citra digital dengn menggunakan metode kuadrat terkecil. Tujuan dari penelitian ini adalah membangun sistem aplikasi pengelolahan citra untuk mendeteksi tingkat kesegaran ikan nila. Data yang gunakan adalah 10 sampel citra ikan nila yang diphoto setiap 1 jam selama 15 jam dan diperoleh 150 data gambar kemudian diolah dan dilakukan analisis dengan metode kuadrat terkecil. Proses pertama diawali dengan pengolahan citra dengan melakukan pemtotongan (cropping) pada bagian tepi mata citra original kemudian dilanjutkan dengan penyamaan ukuran (resize) menjadi $1000 x 1000$ pixel dan pergantian format citra menjadi *.png.setelah gambar sudah diolah kemudian dilakukan perhitungan nilai rata-rata grayscale menggunakakn sistem aplikasi 'Rata rata Gambar' dan diperoleh persamaan yang disimpan sebagai data training pada sistem aplikasi. Setelah citra sudah diolah selanjutnya citra tersebut di-input pada sistem maka citra akan dikonversi kedalam bentuk grayscale dan ditampilkan pada tempat yang telah ditentukan bersamaan dengan histogram rgb dan grayscale kemudian dilakukan perhitungan dengan metode kuadrat terkecil. Proses terakhir kita lakukan pencocokan citra uji dengan citra yang disimpan sebagai data training dan diperoleh kesimpulan apakah citra itu (sangat segar, segar, cukup segar, tidak segar, atau sangat tidak segar), persentase ketidaksegaran ikan selar, dan lama waktu ikan selar mati. Penelitian ini menggunakan 150 sampel citra ikan selar dari ikan masih sangat segar sampai ikan sangat tidak segar (busuk).
\end{abstract}

Kata Kunci: Mata Ikan Nila, Pengolahan Citra Digital, Metode Kuadrat Terkecil.

Abstract-Fish contain many nutrients that are very beneficial for the body, but often fish are traded in a state of death as well as being alive. To observe the freshness of tilapia is done by the introduction of color changes that appear on digital images using the least squares method. The purpose of this research is to build an image management application system to detect the freshness of tilapia. The data used are 10 samples of tilapia images which are photographed every 1 hour for 15 hours and obtained 150 image data and then processed and analyzed using the least squares method. The first process begins with image processing by cropping at the edge of the eye of the original image and then proceed with resizing to $1000 \times 1000$ pixels and changing the image format to *. Png. After the image has been processed then the average value is calculated rata grayscale uses the 'rata_rata Gambar' application system and an equation is stored which is stored as training data on the application system. After the image has been processed then the image is input into the system, the image will be converted into grayscale form and displayed at a predetermined place together with the rgb and grayscale histograms and then calculated using the least squares method. The last process we do is matching the test image with the image stored as training data and we conclude whether the image is (very fresh, fresh, fresh enough, not fresh, or very not fresh), the percentage of freshness of the anchor fish, and the length of time the anchor fish dies. This study used 150 samples of fish images from fresh fish that were still very fresh until the fish were not very fresh (rotten).

Keywords: Tilapia Eye, Digital Image Processing, Least Squares Method.

\section{PENDAHULUAN}

Ikan memiliki bentuk dan ukuran tertentu yang berbeda antara ikan yang satu dengan yang lain. Permasalahan dalam mengenali jenis ikan lebih kompleks dibandingkan dengan mengenali wajah manusia. Perbedaan bentuk, warna, dan tekstur pada ikan lebih bervariasi dibandingkan manusia. Pengenalan jenis ikan pada umumnya masih dilakukan secara manual menggunakan pengamatan mata. Sehingga diperlukan adanya sistem yang dapat mengenali ikan secara otomatis. Dari banyaknya keberagaman dan perbedaan karakteristik dari ikan, sehingga sangat sulit bagi kita untuk mengenali keberagaman ikan tersebut jika tidak mempunyai ilmu tentang perikanan. Padahal dengan mengklasifikasi jenis ikan, kita dapat mempelajari jenis ikan yang sangat beraneka ragam. Klasifikasi ikan juga mempunyai berbagai permasalahan nyata. Misalnya dalam perusahaan produksi pengalengan ikan, selama ini pengenalan jenis ikan masih dilakukan secara manual melalui pengamatan mata.

Dalam bidang perikanan dilihat dari proses penyortiran ikan yang dilakukan oleh nelayan atau penjual, untuk menyeleksi ikan berdasar kualitasnya masih menggunakan metode manual dan terkadang meleset karena faktor keterbatasan indra penglihatan ketika lelah. Selama ini pemeriksaan hanya dillihat secara fisik. Akibatnya, saat akan dikonsumsi ikan tersebut kerap kali sudah rusak[1]. Untuk melindungi konsumen, maka diperlukan suatu rangkaian peralatan elektronika dengan menggunakan mikrokontroler. Mikrokontroler adalah sebuah sistem komputer fungsional dalam sebuah chip. Di dalamnya terkandung sebuah inti prosesor, memori (sejumlah kecil RAM, memori program, atau keduanya), dan perlengkapan input output[2].

a. Perkembangan TI saat ini 
Untuk bisa mengenali jenis-jenis ikan, pada umumnya bisa didapatkan berdasarkan ciri-ciri umum yang dimiliki antara jenis ikan yang satu dengan jenis ikan yang lain. Fitur-fitur yang mendeskripsikan sifat untuk pengenalan ikan antara lain, yaitu: fitur bentuk umum tubuh, sirip, mulut, ekor, dan fitur fisik lainnya. Klasifikasi ikan menetapkan jenis atau kategori ikan dimana tiap-tiap jenis ini meliputi satu atau beberapa kelompok yang terdekat. Pengenalan jenis ikan ini tidak lepas dari ciri fisik ikan mudah dilihat dan dikenali dalam membedakan jenis-jenis ikan. Bentuk fisik ikan ini juga sangat erat kaitannya dengan lingkungan ikan itu berada. Bagian-bagian tubuh ikan akan digunakan dalam proses identifikasi.

b. Objek Penelitian

Permasalahan dalam dunia pangan di Indonesia menjadi salah satu permasalahan yang perlu untuk diperhatikan seperti pemilihan bahan makanan yang nantinya diolah sebelum dikonsumsi. Jika pemilihan bahan makanan atau bahan olahan tidak dilakukan dengan cermat maka hal ini tentu akan membahayakan bagi kesehatan tubuh manusia. Oleh karena itu aplikasi pengolahan citra tentang penentu kesegaran ikan ini dipilih untuk ikut menjaga kesehatan tubuh manusia secara tidak langsung. Deteksi kesegaran ikan adalah sebuah teknologi yang digunakan sebagai penentu kualitas kesegaran ikan dengan cara pengenalan memalui gambar atau citra

c. Masalah pada objek

Seiring berkembangnya zaman yang semakin canggih maka untuk menentukan kesegaran ikan nila yang dipasarkan supaya menggunakan teknologi agar lebih cepat dan efisien dalam hasil yang diberikan. Dikarenakan banyak manusia terkhusus untuk kalangan ibu-ibu yang belanja ke pasar tradisional yang mengkhawatirkan kesegaran ikan nila yang akan dibeli. Dengan permasalahan yang semakin memuncak ini banyak kalangan ibu-ibu lebih menghindari untuk membeli ikan nila suapaya tidak salah memilih ikan nila yang masih segar dan bahkan tidak makan untuk mengurangi kesalahan dalam pemilihan ikan nila yang masih segar untuk dimakan.

d. Usulan perbaikan masalah (build app)

Dalam masalah Teknologi ini agar bisa digunakan untuk salah satunya adalah pengunjung supermarket, pasar tradisional, ataupun masyarakat yang ingin membeli atau ingin tahu tentang bagaimana kualitas kesegaran ikan yang masih layak untuk dijual ataupun yang ingin dibeli.

e. Harapan terhadap apilkasi

Dengan adanya aplikasi ini maka akan banyak harapan yang baik dalam kehidupan sehari-hari manusia, misalnya ketika kita membeli ikan dipasar maka kita akan lebih dimudahkan dalam pemakaian dan cara kerja aplikasi untuk menghasilkan ikan nila yang masih segar dan sanyak layak untuk dikonsumsi. Dan ditambah lagi dengan adanya aplikasi ini yang sangat memudahkan kita dalam memilih ikan nila yang sangat efektif dan efisien.

\subsection{Analisis Data}

\section{METODE PENELITIAN}

Data dalam penelitian ini menggunakan 10 sampel citra ikan nila. Citra mata ikan nila dimanfaatkaan sebagai input data untuk menghitung nilai rata-rata Grayscale yang memberikan informasi berupa nilai-nilai.. Hasil output nilai Grayscale diolah dengan metode kuadrat terkecil untuk menghitung tingkat kesegaran ikan yang kemudian dicocokan dengan data inferensi yang sebelumnya disimpan dalam data training dan output terakhir merupakan sebuah citra yang berisikan informasi keterangan tentang tingkat kesegaran ikan nila.

\subsection{Metode Penelitian}

Langkah 1 - 6 menunjukan pengolahan citra untuk membangun sistem klasifikasi tingkat kesegaran ikan sedangkan langkah 9 - 12 menunjukan klasifikasi sistem aplikasi penentuan tingkat kesegaran ikan. langkah-langkahnya sebagai berikut :

1. Mengambil 11 data citra digital mata ikan nila dengan model warna RGB yang berekstensi JPG (Joint Photografhic Expert Group).

2. Dilakukan pengolahan citra dengan memotong (cropping) pada bagian tepi mata ikan nila. 
3. Penyamaan pixel citra digital.

4. Cari nilai rata-rata grayscale untuk setiap tekstur citra mata ikan nila dari citra mata ikan nila yang segar (prima) sampai tidak segar (busuk) kemudian buat persamaan.

5. Buat persamaan regresinya dengan metode kuadrat terkecil kemudian disimpan sebagai data training

6. Input citra pada sistem aplikasi.

7. Konversi RGB ke Grayscale.

8. Tampilkan Histogram Citra RGB dan Grayscale

9. Perumusan tingkat kesegaran ikan dengan metode kuadrat terkecil berdasarkan nilai rata-rata citra digital mata ikan nila.

10. Menyamakan data uji dengan data training citra yang sudah disimpan sebelumnya.

11. Menentukan dan menyimpulkan tingkat kesegaran ikan dengan perumusan dari inferensi data sebelumya[3].

\section{HASIL DAN PEMBAHASAN}

Ikan memiliki bentuk dan ukuran tertentu yang berbeda antara ikan yang satu dengan yang lain. Permasalahan dalam mengenali jenis ikan lebih kompleks dibandingkan dengan mengenali wajah manusia. Perbedaan bentuk, warna, dan tekstur pada ikan lebih bervariasi dibandingkan manusia[4]. Berdasarkan penjelasan diatas oleh karena itu perlu dibutuhkan nya alat pendeteksi kesegaran ikan. Pada uji algoritma klasifikasi penelitian dibawah ini menggunakan 11 data dengan 11 ikan yang berbeda. Pada penelitian ini tahap yang pertama adalah pembuatan diagram alur (flowchart). Berikut gambar flowchartnya.

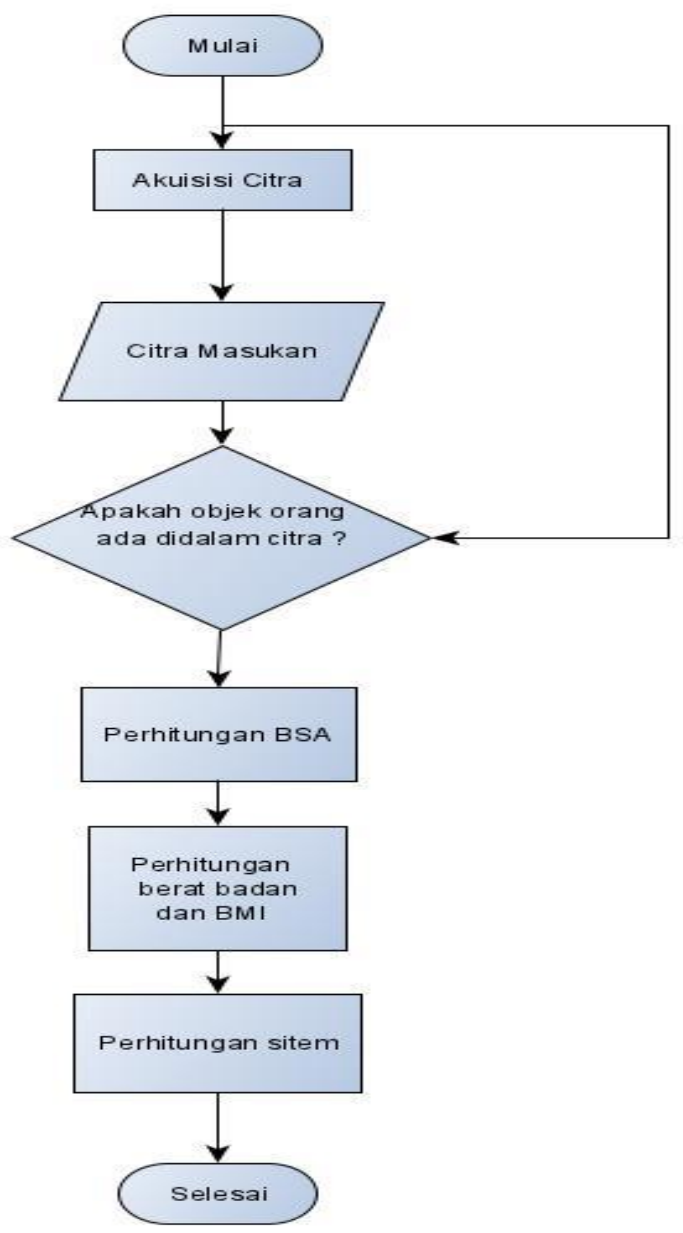

Gambar 1. Flowchart 


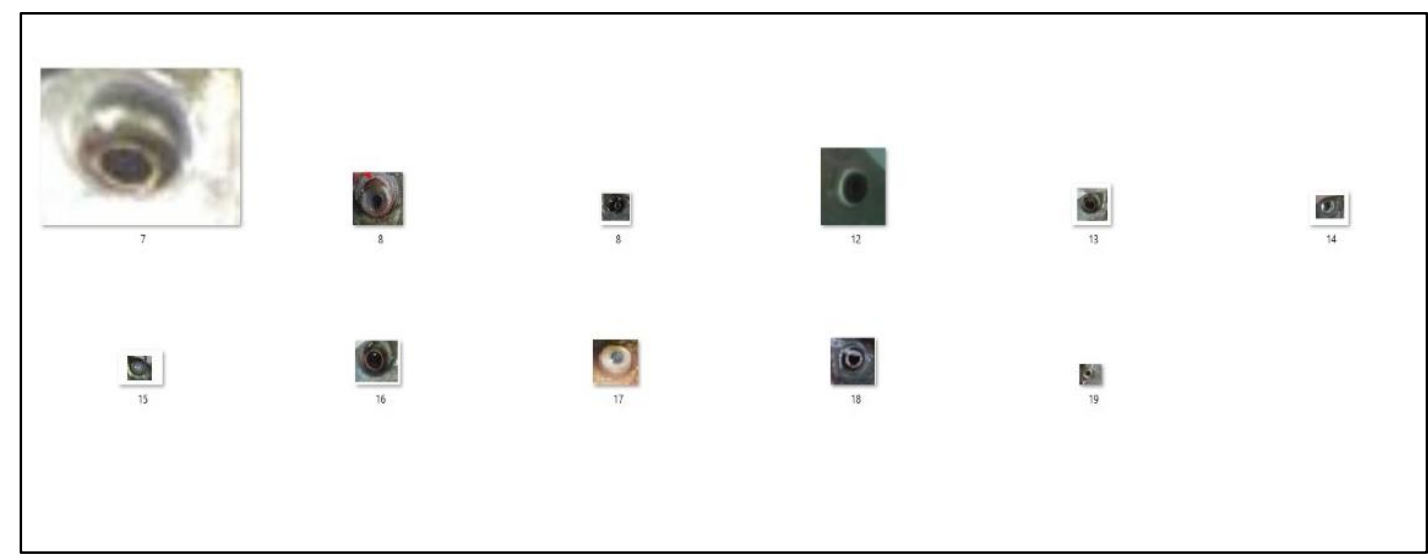

Gambar 2. Data Mata Ikan Nila

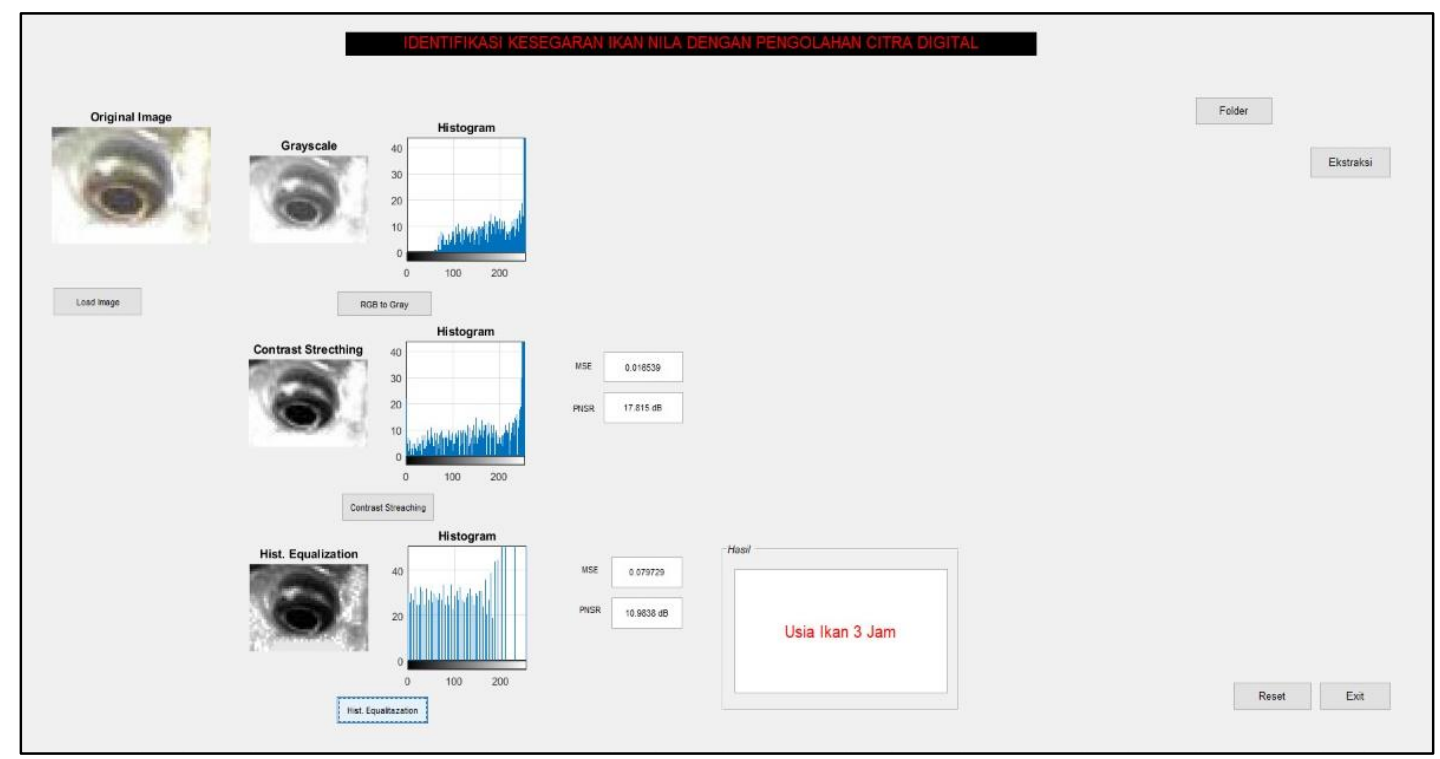

Gambar 3. Tampilan Aplikasi Citra

Tahap pengujian sistem akan dilakukan dengan pengujian terhadap 11 citra ikan Nila yang berekstensi JPG. dimana 11 citra tersebut diperoleh dari pengambilan citra mata ikan Nila sebanyak 11 sampel ikan dan difoto setiap satu jam selama 15 jam dari ikan itu masih dalam kondisi segar hingga ikan itu membusuk. Dari 11 data citra mata ikan Nila tersebut dilakukan pengolahan citra dengan melakukan penyamaan ukuran pixelnya dan pemotongan terhadap bagian mata ikan, setelah pengolahan citra tersebut, citra yang berekstensi JPG dikonversi ke bentuk grayscale selanjutnya ditampilkan histogram RGB dan grayscale-nya kemudian dilakukan perhitungan dan analisis dengan metode kuadrat terkecil. Pada bagian terakhir dilakukan pencocokan citra hasil input dengan citra yang sudah disimpan sebagai data training. Perhitungan dan analisis metode kuadrat terkecil tersebut mampu mendeteksi perubahan warna citra dengan membandingkan data range nilai rata-rata tekstur mata ikan yang menjadi acuan dalam menentukan tingkat kesegaran suatu ikan Nila.

Ikan segar (pre rigor) merupakan ikan yang belum mengalami perubahan fisik maupun kimia yang kondisinya masih seperti saat ikan ditangkap. Sedangkan ikan tidak segar (post rigor) ikan yang sudah mengalami perubahan fisik seperti warna bagian mata kemerah-merahan, insang berwarna cokelat/suram, sisik mudah lepas. Pengujian ini terbagi 2 yaitu pengujian deteksi ikan segar dan ikan tidak segar.

a) Ikan segar dan hasil threshold 

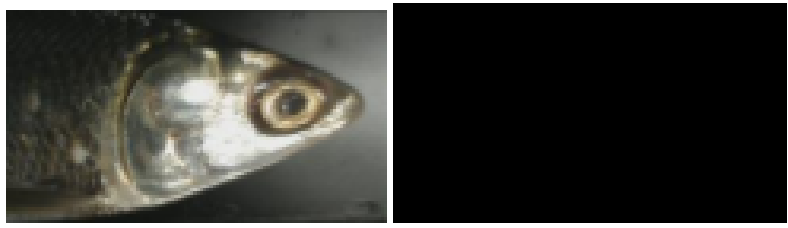

Gambar. 4 Tampilan Ikan Segar Dan Hasil Threshold

b) Ikan tidak segar dan hasil threshold
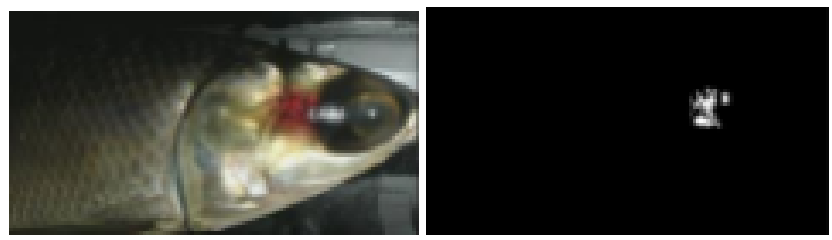

Gambar. 5 Tampilan Ikan Tidak Segar Dan Hasil Threshold

\section{KESIMPULAN}

Berdasarkan uji coba dan analisis hasil pengujian pada metode klasifikasi ikan menggunakan ORB dan KNN, dapat diuraikan beberapa kesimpulan. Algoritma ORB dapat mendeteksi keypoint dan menghasilkan fitur yang invariant terhadap perubahan sudut rotasi pada citra ikan. Terbukti dengan pengujian klasifikasi ikan dengan perbedaan rotasi, hasil tetap menunjukkan nilai akurasi yang tinggi. Klasifikasi ikan menggunakan KNN dari hasil penelitian ini sangat akurat. Dari hasil uji coba pengujian, walaupun memiliki komputasiyang lebih lama, metode yang diusulkan memiliki tingkat keberhasilan dalam mengklasifikasi seluruh sampel data ikan dengan tingkat akurasi sangat bagus.

\section{DAFTAR PUSTAKA}

[1] S. Dwiyanto, Iksal, and S. Nugraha, "Alat Pendeteksi Kesegaran Ikan Menggunakan Metode K-Nearest Neighbor Berdasar Warna Mata Berbasis ATMega 328," J. PROSISKO, vol. 5, no. 2, pp. 127-135, 2018.

[2] V. D. M. A. S. M. Lumenta, A. M. Rumagit, and J. T. Elektro-ft, "Perancangan Sistem Monitoring Mengajar Berbasis Mikrokontroler Atmega 8535," E-Journal Tek. Elektro Dan Komput., vol. 3, no. 3, pp. 19-25, 2014, doi: 10.35793/jtek.3.3.2014.4884.

[3] D. Bee, W. Weku, and A. Rindengan, "Aplikasi Penentuan Tingkat Kesegaran Ikan Selar Berbasis Citra Digital Dengan Metode Kuadrat Terkecil," d'CARTESIAN, vol. 5, no. 2, p. 121, 2016, doi: 10.35799/dc.5.2.2016.14985.

[4] M. Ramadhani and D. H. Murti, "Klasifikasi Ikan Menggunakan Oriented Fast and Rotated Brief (Orb) Dan K-Nearest Neighbor (Knn)," JUTI J. Ilm. Teknol. Inf., vol. 16, no. 2, p. 115, 2018, doi: 10.12962/j24068535.v16i2.a711.

[5] I. Indrabayu, M. Niswar, and A. A. Aman, "Sistem Pendeteksi Kesegaran Ikan Bandeng Menggunakan Citra," J. INFOTEL - Inform. Telekomun. Elektron., vol. 8, no. 2, pp. 170-179, 2016, doi: 10.20895/infotel.v8i2.119.

[6] H. D. Hutahaean, B. D. Waluyo, and M. A. Rais, "Teknologi Identifikasi Objek Berbasis Drone Menggunakan Algoritma Sift Citra Digital," vol. 04, pp. 202-207, 2019.

[7] P. Informatika, B. Darma, H. D. Hutahaean, C. Digital, C. Streching, and L. Teori, "TEKNIK PENAJAMAN CITRA DIGITAL DENGAN MENGGUNAKAN Diterbitkan Oleh : STMIK Budi Darma Medan Diterbitkan Oleh : STMIK Budi Darma Medan,” vol. III, pp. 35-44, 2013. 